\title{
Efeito de dois tipos de quebra de dormência na germinação de guapuruvu (Schizolobium parahyba)
}

O guapuruvu (Schizolobium parahyba) é uma árvore nativa da Mata Atlântica amplamente utilizada em programas de reflorestamento graças ao seu rápido crescimento inicial. No entanto, como a maioria das espécies florestais, estas plantas possuem um tipo de dormência tegumentar característico da família a qual pertencem, a fabaceae. Para superar esta dormência, são encontrados na literatura vários métodos de tratamentos pré-emergência. Neste sentido, o presente trabalho teve por objetivo avaliar o efeito de dois tipos de quebra de dormência na germinação de Schizolobium parahyba. Os tratamentos consistiram na imersão das sementes em ácido sulfúrico a $10 \%$ por $45 \mathrm{~min}$ e escarificação mecânica com lixa, além do tratamento testemunha. $O$ delineamento experimental utilizado foi inteiramente casualizado com quatro repetições, e para cada repetição foram semeadas dez sementes. Foi calculada a porcentagem de germinação e a velocidade de germinação. Os dados obtidos foram submetidos ao teste de Tukey a $5 \%$ de probabilidade. $O$ tratamento que obteve maior percentagem de germinação foi o de imersão em ácido sulfúrico, totalizando $98 \%$ de germinação das sementes, apesar de significativamente diferentes, o tratamento por escarificação mecânica também apresentou índices de germinação considerável, com 60,5\%. Conclui-se que as sementes de Schizolobium parahyba necessitam passar por algum processo de quebra de dormência e que ambos os tratamentos podem se mostrar eficientes, podendo chegar a quase $100 \%$ de germinação com uso de ácido sulfúrico a $10 \%$ por um período de imersão de $45 \mathrm{~min}$.

Palavras-chave: Quebra de dormência; Germinação; Schizolobium parahyba.

\section{Effect of two types of dormancy breaking on the germination of guapuruvu (Schizolobium parahyba)}

\begin{abstract}
The guapuruvu (Schizolobium parahyba) is a native tree of the Atlantic Forest widely used in reforestation programs thanks to its rapid initial growth. However, like most forest species, these plants have a type of integumentary dormancy characteristic of the family to which they belong, the fabaceae. To overcome this numbness, several methods of pre-emergence treatments are found in the literature. In this sense, the present work had the objective of evaluating the effect of two types of dormancy breaking on the germination of Schizolobium parahyba. The treatments consisted of immersion of the seeds in $10 \%$ sulfuric acid for 45 minutes and mechanical scarification with sandpaper, in addition to the control treatment. The experimental design was completely randomized with four replicates, and for each replicate ten seeds were sown. The percentage of germination and the speed of germination were calculated. The data were submitted to the Tukey test at $5 \%$ probability. The treatment with the highest percentage of germination was immersion in sulfuric acid, totaling $98 \%$ germination of the seeds, although significantly different, the treatment by mechanical scarification also presented considerable germination rates, with $60.5 \%$. It is concluded that the seeds of Schizolobium parahyba need to undergo some process of dormancy breaking and that both treatments can be efficient, reaching almost $100 \%$ of germination with $10 \%$ sulfuric acid for a period of immersion of $45 \mathrm{~min}$.
\end{abstract}

Keywords: Breakage of numbness; Germination; Schizolobium parahyba.

Topic: Engenharia Ambiental

Reviewed anonymously in the process of blind peer.

Jefferson Carlos

Faculdade Guaraí, Brasil

http://lattes.cnpq.br/8788260510456729

jeffersonmonitor@gmail.com

Erick Dias Silva

Faculdade Guaraí, Brasil

http://lattes.cnpq.br/3952797298651773

eridias57@gmail.com

Laura Oliveira Silveira

Instituto Federal de Rondônia, Brasil

http://lattes.cnpq.br/3473714491524893

laurasilveirazootec@gmail.com
Received: 14/12/2017

Approved: 23/12/2017
Referencing this:

CARLOS, J.; SILVA, E. D.; SILVEIRA, L. O.. Efeito de dois tipos de quebra de dormência na germinação de guapuruvu (Schizolobium parahyba). Natural Resources, v.7, n.2, p.43-51, 2017. DOI:

http://doi.org/10.6008/SPC2237-9290.2017.002.0005 


\section{INTRODUÇÃO}

O guapuruvu (Schizolobium parahyba) é uma árvore da família das Fabaceas, conhecida por sua velocidade de crescimento (que pode atingir até três metros por ano) e pouca exigência em relação a condições edáficas, desta forma, tem sido grandemente utilizada em programas de reflorestamento de áreas degradadas, indústria madeireira, celulose, entre outras finalidades (MATHEUS et al., 2007).

No geral, as sementes de espécies florestais germinam sob condições favoráveis. No entanto, quando a germinação não ocorre, as sementes são caracterizadas em estado de dormência (BIANCHETTI, 1981). A dormência de sementes é tida como um impedimento físico ou fisiológico à germinação, utilizada pelas plantas para beneficiar a propagação de material genético ou resistir a adversidades ambientais.

Muitas espécies florestais produzem sementes que impõem restrições à passagem de água através do tegumento. Este fenômeno é controlado geneticamente, varia conforme a espécies e as variedades. As sementes de guapuruvu apresentam dormência em função da impermeabilidade do tegumento a água, fenômeno que dificulta o processo germinativo e a propagação das espécies, resultando em atraso e desuniformidade na germinação.

Na família Fabaceae, antiga família das leguminosas, a dormência gerada pela impermeabilidade do tegumento é bastante comum, constituindo, possivelmente, o único tipo de dormência presente nesta família (NASCIMENTO et al., 1999). Alguns tratamentos que promovem ranhuras ou rompimento do tegumento são indicados para permitir a penetração de água.

A principal resistência a entrada de água em Fabaceae é conferida pela testa. Esta é constituída por células parenquimatosas dispostas em paliçada, que apresentam paredes celulares lignificadas e com alta deposição de substâncias hidrofóbicas, tais como lipídios, suberina, cutina, substâncias pécticas e lignina (CARDOSO, 2004; CARVALHO et al., 2000).

Em ambiente natural, essa dormência é quebrada por processos de escarificação, a qual consiste em qualquer tratamento que ocasione a ruptura ou o enfraquecimento do tegumento que permitirão a entrada de água e gases, dando início ao processo de germinação. Nestes ambientes, a escarificação pode ocorrer pelo aquecimento úmido ou seco do solo, por temperaturas alternadas, ou, por exemplo, pelos incêndios naturais que ocorrem no Cerrado.

Outros processos também podem ocorrer como a ação da ingestão de ácidos em função da ingestão de sementes por animais dispersores, além da ação de microrganismos no solo (ALVES et al., 2006). Em laboratório, foram desenvolvidos vários métodos que visam a superação desse tipo de dormência em sementes, como a imersão em ácidos, bases fortes, álcool, água oxigenada, água fria ou quente, présecagem, desponte e impactos sobre a superfície sólida, entre outros.

Segundo Eira et al. (1993), todos esses tratamentos possuem vantagens e desvantagens, de forma que cada um deles deve ser estudado separadamente, para cada espécie, levando-se em consideração também, o custo efetivo e o grau de dificuldade na execução. Além do mais, em um mesmo lote pode haver sementes em diferentes níveis de dormência, desta forma, o método escolhido deve ser eficiente para a 
quebra de dormência, sem prejudicar as aquelas sementes que apresentam dormência menos acentuadas (ALVES et al., 2006).

No entanto, Labouriau (1983) relata a existência de diversos tratamentos que podem ser realizados com o objetivo de eliminar a impermeabilidade do tegumento. Tratamentos estes que são mais baratos, seguros e rápidos, como a escarificação com lixa, lima ou outro instrumento abrasivo; aquecimento ou fervura em água; submeter o material a pressões hidrostáticas elevadas; vibrações de alta frequência; ataque por ácido sulfúrico e lavagem em etanol.

Vários trabalhos com sementes de Schizolobium parahyba apontam a necessidade de tratamentos pré-germinativos que possam promover condições de superar a impermeabilidade do tegumento e, desta forma, fornecer condições para a germinação. Entre os principais tratamentos recomendados para quebra de dormência nesta espécie, cita-se a imersão em ácido sulfúrico (FREITAS et al., 1972), desponte, e imersão em água à temperatura de ebulição (BIANCHETTI et al., 1981).

A quebra de dormência, além do incremento na percentagem de germinação, tem a vantagem de aumentar a velocidade de crescimento, promovendo maior uniformidade inicial da população e maiores chances de sobrevivência. Neste sentido, o presente trabalho teve como objetivo estudar a germinação de sementes de Schizolobium parahyba após serem submetidas a dois tratamentos pré-germinativos.

\section{MATERIAIS E MÉTODOS}

Foi realizada quebra de dormência em sementes de Schizolobium parahyba no Laboratório de Solos do Instituto Educacional Santa Catarina/Faculdade Guaraí, localizado na cidade de Guaraí/TO, conforme mostra a figura 1. A cidade de Guaraí fica localizada na Região Norte do Brasil, mesorregião de Miracema do Tocantins, região ocidental do estado. O Tocantins é o estado mais jovem da federação, com 27 anos de emancipação e faz parte do acrônimo MATOPIBA, considerado pelo Ministério da Agricultura como a última fronteira agrícola do mundo, da qual também fazem parte o estado do Maranhão, Piauí e Bahia.

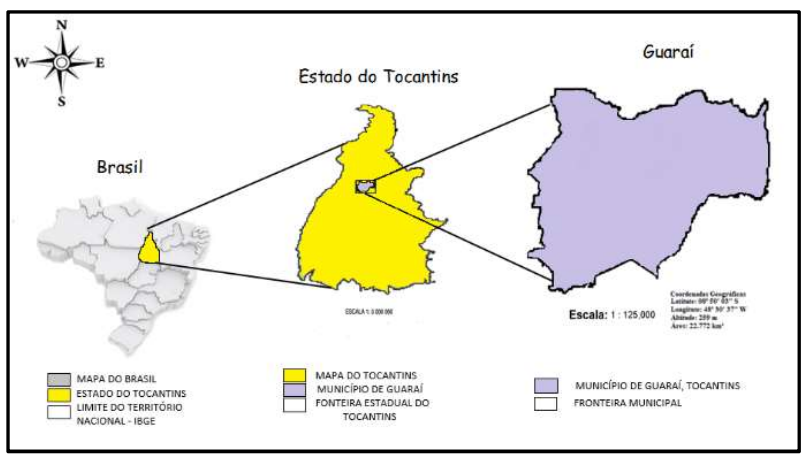

Figura 1: Mapa do Brasil, de Tocantins e de Guaraí, onde se procedeu a pesquisa. Fonte: Silveira et al. (2017).

Os tratamentos foram: ausência de escarificação (testemunha); escarificação com lixa; e imersão em ácido sulfúrico a $10 \%$ durante $45 \mathrm{~min}$. As sementes utilizadas foram doadas especialmente para a realização deste trabalho e foram colocadas para germinar logo após a aplicação dos tratamentos. O delineamento 
experimental utilizado foi inteiramente casualizado, com quatro repetições, sendo utilizadas dez sementes por repetição em cada tratamento.

Após a aplicação do tratamento com ácido sulfúrico, as sementes foram lavadas em água corrente por cinco minutos e em seguida todas as sementes foram semeadas em saquinhos próprios para esta finalidade, tendo como substrato um solo de textura média da área experimental da Faculdade Guaraí. Os saquinhos foram colocados em canteiro com cobertura que barra $50 \%$ da incidência solar, em temperatura e foto período ambiente. A irrigação foi feita diariamente de modo a manter $75 \%$ da capacidade de campo. A verificação do número de sementes germinadas foi feita diariamente durante um período de 20 dias, até a conclusão do experimento, calculando-se a porcentagem de germinação e o índice de velocidade de emergência.

O índice de velocidade de emergência (IVE) foi determinado em conjunto ao teste de emergência das plântulas, para cada tratamento, somando-se o número de plântulas emergidas a cada dia, divididas pelo respectivo número de dias transcorridos desde a semeadura. Estes dados geraram um índice de vigor, conforme proposto por Maguire (1962). A velocidade de germinação foi calculada segundo Popinigis (1977, citado por NASCIMENTO et al., 1999). Para a análise de variância, os dados foram transformados em arco seno e as médias comparadas pelo teste de Tukey a $5 \%$.

\section{RESULTADOS}

A emergência das plântulas a partir de sementes não escarificadas (tratamento testemunha) foi de $5 \%$, confirmando o elevado grau de dormência da espécie estudada conforme citado por outros autores. Segundo Paoli (2006) as sementes de espécies leguminosas possuem epiderme formada por células com parede espessa e lignificadas e, além disso, essas células muitas vezes são preenchidas por compostos fenólicos, intensificando o estado de dormência.

Tabela 1: Percentagem de emergência de sementes de Schizolobium parahyba submetidas a dois tipos de tratamento pré-emergencial. Letras diferentes na linha diferem entre si pelo teste de Tukey a $5 \%$ de probabilidade.

\begin{tabular}{|c|c|c|c|}
\hline \multirow{2}{*}{ S. parahyba } & Testemunha & Lixa & Ácido Sulfúrico \\
\cline { 2 - 4 } & $5,0 \mathrm{C}$ & $60,5 \mathrm{~B}$ & $98,0 \mathrm{~A}$ \\
\hline C.V (\%) & 4,8 & 6,1 & 5,5 \\
\hline
\end{tabular}

A escarificação mecânica obteve resultados bastante satisfatórios, conforme pode ser observado na tabela 1, com $60 \%$ de germinação. Para este tratamento, a germinação se iniciou no quinto dia após a semeadura e o pico de germinação ocorreu no oitavo dia. Apesar do resultado satisfatório, o tratamento com imersão em ácido sulfúrico por $45 \mathrm{~min}$ foi o que obteve valores mais altos, chegando a $98 \%$ de plantas germinadas. Este também foi o tratamento que resultou em uma emergência mais precoce, sendo iniciada ao terceiro dia pós-semeadura, com pico de emergência ao sexto dia, conforme ilustrado na figura 1. 


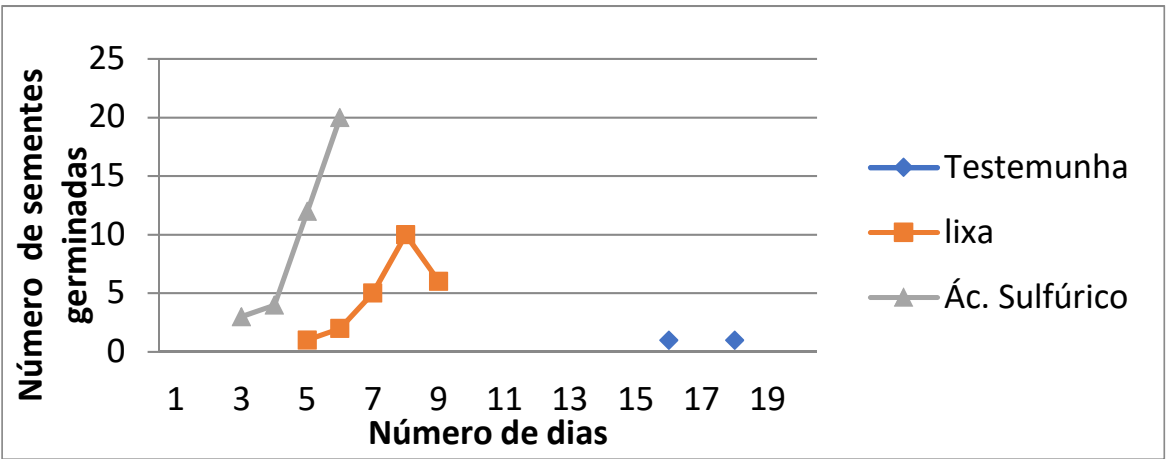

Figura 2: Velocidade de germinação de Schizolobium parahyba em função dos tratamentos pré-emergenciais.

\section{DISCUSSÃO}

Algumas espécies retardam a germinação de suas sementes até que as condições do ambiente estejam adequadas para o seu estabelecimento e sobrevivência. Este mecanismo denominado dormência, já descrito anteriormente, constitui uma estratégia adaptativa benéfica às sementes, pois possibilita a distribuição da germinação ao longo do tempo, aumentando assim as chances de sobrevivência das espécies. Assim, a dormência se apresenta vantajosa para a perpetuação e o estabelecimento de muitas espécies vegetais nos mais variados ambientes (ZAIDAN et al., 2004), aumentando a possibilidade de surgimento de novos indivíduos ou a ocupação de novas áreas por distribuir a germinação no tempo e no espaço (CARVALHO et al., 2000). No entanto, a dormência mostra-se como uma característica indesejável para a agricultura, uma vez que para atingir os parâmetros de produção e produtividade, são requeridos rápida germinação, rápido crescimento e homogeneidade das plantas.

O processo de germinação é um evento, puramente físico, onde ocorre a reidratação da semente. Ela acontece através de um processo de embebição e é dependente de três fatores: composição química da semente; permeabilidade do tegumento e presença de água no meio em que o processo irá ocorrer. Com a absorção de água, as substâncias coloidais aumentam de volume, produzindo a pressão da embebição, que resulta no rompimento do tegumento da semente. A impermeabilidade do tegumento, tegumento duro, presença de inibidores e a imaturidade do embrião inibem o processo de germinação, causando o fenômeno chamado de dormência (FRANCO et al., 2002). No presente experimento, as sementes que não passaram por qualquer tipo de tratamento de pré-emergência tiveram uma germinação bastante baixa, demonstrando então a resistência importa a germinação pelo tegumento.

Álvares et al. (2015), estudando dois métodos de quebra de dormência, sendo eles a escarificação mecânica com lixa e choque térmico, em sementes de Guapuruvu (Schizolobium parahyba) obtiveram $68,34 \%$ de germinação, sendo superior ao tratamento com choque térmico e ao tratamento controle, resultado bastante semelhante ao obtido no presente experimento, onde a porcentagem de germinação para este tratamento foi de $60,5 \%$. Os referidos autores atribuem a maior percentagem de germinação às sementes submetidas à escarificação justamente a maior capacidade de absorção de água por estas sementes, após a impermeabilidade do tegumento ser superada, permitindo o processo germinativo. Azeredo et al. (2003) também relatam a efetividade destes tratamentos para diversas espécies arbóreas. 
Em concordância, Sebastiani et al. (2016) avaliou dois métodos de quebra de dormência (escarificação com lima e imersão em água fervente) e diferentes tipos de substratos (substrato vegetal e substrato obtido em monocultura de Eucalyptus sp.), na germinação de Schizolobium parahyba. Sebastiani et al. (2016) encontraram resultados bastante semelhantes ao presente experimento, onde a escarificação mecânica obteve as maiores taxas de germinação, entre 58 e 62\%, respectivamente para cada substrato. Sebastiani et al. (2016) também relatam que a germinação teve início entre o sexto e o 12임, com o pico de germinação ocorrendo no sétimo dia. Neste trabalho a porcentagem de germinação, como dita anteriormente foi de $60,5 \%$ e a germinação ocorreu entre o quinto e o 10 일, sendo o pico de germinação ao oitavo dia.

Negreiros et al. (2015), avaliando a superação da dormência de Schizolobium amazonicum por meio de três tipos diferentes de tratamento pré-emergência (imersão em ácido sulfúrico por 60min; imersão em água por 24h; escarificação mecânica) além do tratamento controle, obtiveram resultados que diferiram daqueles encontrados neste trabalho. Negreiros et al. (2015) relatam que a penas o método de escarificação mecânica possibilitou a obtenção de $100 \%$ de emergência durante o período de avaliação, sendo superior aos demais tratamentos.

A imersão em ácido sulfúrico resultou em apenas $80 \%$ de germinação. No presente trabalho, o tratamento que obteve maior percentagem de germinação foi o de ácido sulfúrico, no entanto, vale ressaltar que o tempo de imersão foi menor, totalizando $45 \mathrm{~min}$, em comparação aos $60 \mathrm{~min}$ praticados por Negreiros et al. (2015). Avaliou-se a imersão de sementes de jatobá em ácido sulfúrico por 10, 20, 30 e 40 minutos relatam que para esta espécie houve incremento na percentagem de germinação até o tempo de imersão de 30 minutos, sendo que apões este período houve redução na percentagem de germinação das sementes. Negreiros et al. (2015) atribuem ao fato de que períodos superiores ao necessário para superar a dormência, além da degradação do tegumento, podem ocasionar danos, como a ruptura de células essências, reduzindo a germinação.

A escarificação mecânica e química, bem como a imersão em água quente são métodos bastante conhecidos e utilizados com sucesso para a superação da dormência imposta pelo tegumento. No entanto, como já foi dito, a aplicação e eficiência destes métodos dependem da intensidade da dormência, que é variável de acordo com a espécie, da procedência das sementes e do ano de sua coleta - em geral, quanto mais velhas forem as sementes, menos viáveis elas serão.

No caso da escarificação ácida, ocorre o desgaste do tegumento, promovendo a permeabilidade da semente. Diversos estudos relatam que o ácido sulfúrico é bastante eficiente para superar a dormência de sementes florestais (KISSMAN et al., 2008; MATINS et al., 2008; BENEDITO et al., 2009; NASCIMENTO et al., 2009). Segundo Nascimento et al. (2009), o sucesso do tratamento está relacionado com o tempo de exposição da espécie ao ácido.

O ácido sulfúrico foi utilizado com eficiência para superação da dormência de sementes de Guazuma ulmifolia Lam. (ARAÚJO NETO et al., 2000), de Dimorphandra mollis Benth. (HERMANSEN et al., 2000), de 
Leucaena leucocephala (Lam.) de Wit. (TELES et al., 2000), de Tachigalia multijuga Benth. (BORGES et al., 2004), de Zizyphus joazeiro Mart. (ALVES et al., 2006), de Ormosia nitida Vog. (LOPES et al., 2006), de Caesalpinia pyramidalis Tul. (ALVES et al., 2007), de Senna siamea Lam. (DUTRA et al., 2007), de Bauhinia spp. (LOPES et al., 2007), de Albizia lebback (L.) Benth. (DUTRA et al., 2008), de Dimorphandra mollis Benth. (SCALON et al., 2007) e de Leucaena diversifolia L. (SOUZA et al., 2007). No entanto, para sementes das espécies de Bauhinia variegata L. (MARTINELLE-SEMENEME et al., 2006), Guazuma ulmifolia Lam. e Heteropterys byrsonimifolia A. Juss. (NUNES et al., 2006) e Schinopsis brasiliense Engl. (ALVES et al., 2007b), o tratamento de pré-emergência com ácido sulfúrico não foi eficiente.

Montes et al. (1995) verificaram aumento da germinação de sementes de fava d'anta (Dimorphandra gardneriana Tul.) de $0 \%$ para $93 \%$ após tratamento com ácido sulfúrico. No presente experimento, o tratamento pré-emergência das sementes com imersão em ácido sulfúrico aumentou a germinação de $5 \%$ para 98\%, demonstrando a eficiência deste método também para sementes de Schizolobium parahyba. Outros autores (SABIITI, 1983; RODRIGUES et al., 1990; KONDO, 1993; DUTRA et al., 1994) também obtiveram aumentos na percentagem de germinação após tratar sementes de leguminosas com ácido sulfúrico.

\section{CONCLUSÕES}

As sementes de Schizolobium parahyba necessitam passar por processo de quebra de dormência para que possam alcançar valores percentuais de germinação satisfatórios. O tratamento mais indicado para a quebra de dormência desta espécie é o de imersão em ácido sulfúrico a 10\% por $45 \mathrm{~min}$. 0 tratamento com escarificação mecânica também pode ser utilizado em substituição ao tratamento com ácido sulfúrico, no entanto, resulta em porcentagens de germinação inferiores.

\section{REFERÊNCIAS}

ÁLVARES, S. R.; DIAS, K. R.; SANTOS, J. S.; PASIN, L. A. P.. Efeito de diferentes métodos de quebra de dormência em guapuruvu (Schizolobium parahyba). Univap, São José dos Campos, v.13, n.24, p.245-247, 2006.

ALVES, A. F.; ALVES, A. F.; GUERRA, E. C.; FILHO, S. M. Superação de dormência de sementes de braúna (Schinopsis brasiliense Engl.). Revista Ciência Agronômica, v.38, n.1, p.74-77, 2007.

ALVES, A. U.; DORNELAS, C. S. M.; BRUNO, R. L. A.; ANDRADE, L. A.; ALVES, E. U.. Superação de dormência em sementes de Bauhinia divaricata L.. Acta Botânica Brasílica, v.18, n.4, p.871-879, 2004.

ALVES, E. U.; BRUNO, R. L. A.; OLIVEIRA, A. P.; ALVES, A. U.. Ácido sulfúrico na superação de dormência de unidades de dispersão de juazeiro (Zizyphus joazeiro Mart.). Revista Árvore, Viçosa, v.30, n.2, p.187-195, 2006.

ALVES, E. U.; BRUNO, R. L. A.; OLIVEIRA, A. P.; ALVES, A. U.; ALVES, A. U.. Ácido sulfúrico na superação da dormência de unidades de dispersão de Juazeiro (Zizyphus joazeiro Mart.). Revista Árvore, Viçosa, v.30, n.2, p.187-195, 2006

ALVES, E. U.; CARDOSO, E. A.; BRUNO, R. L. A.; ALVES, A. U.; GALINDO, E. A.; BRAGA, J. M.. Superação de dormência em sementes de Caesalpinia pyramidalis Tul.. Revista Árvore, v.31, n.3, p.405-415, 2007.

ARAUJO NETO, J. C.; AGUIAR, I. B.. Germinative pretreatments to dormancy break in Guazuma ulmifolia Lam. Seeds. Scientia Forestalis, n.58, p.15-24, 2000.

BENEDITO, C. P.; RIBEIRO, M. C. C.; OLIVEIRA, M. K. T.; GUIMARÃES, I. P.; RODRIGUES, G. S. O.. Influência da cor e métodos de superação de dormência em sementes de albizia. Caatinga, v.22, n.2, p.121-124, 2009.

BIANCHETTI, A.. Métodos para superar a dormência de sementes de bracatinga (Mimosa scabrella Benth.). Colombo: EMBRAPA-URPFCS, 1981. 
BIANCHETTI, A.; RAMOS, A.. Quebra de dormência de sementes de guapuruvu (Schizolobium parahyba (Vellozo) Blake). Boletim de Pesquisa Florestal, n.3, p.69-76, 1981.

BORGES, E. E. L.; RIBEIRO JUNIOR, J. I.; REZENDE, S. T.; PEREZ S. C. J. G. A.. Alterações fisiológicas em sementes de Tachigalia multijuga (Benth.) (mamoneira) relacionadas aos métodos de superação de dormência. Revista Árvore, v.28, n.3, p.317-325, 2004.

CARDOSO, V. J. M.. Dormência: estabelecimento do processo. In: FERREIRA, A. G.; BORGUETTI, F.. Germinação: do básico ao aplicado. Porto Alegre: Artmed, 2004. p.95-134

CARVALHO, N. M.; NAKAGAWA, J.. Sementes: ciência, tecnologia e produção. Jaboticabal: FUNEP, 2000.

DUTRA, A. A.; MEDEIROS FILHO, S.; DINIZ, F. O.. Germinação de sementes de albízia (Albizia lebbeck (L.) Benth.) em função da luz e do regime de temperatura. Caatinga, v.21, n.1, p.75-81, 2008.

DUTRA, A. S. R. J. R.; CASTRO, R. P.; SOUZA, M. C. R.. Superação de dormência em sementes de jucá. In: REUNIÃO NORDESTINA DE BOTÂNICA, 18. Anais. Areia: 1994.

DUTRA, A. S.; MEDEIROS FILHO, S.; TEÓFILO, E. M.; DINIZ, F. O.. Germinação de sementes de Senna siamea (Lam.) H.S. Irwin e Barneby Caesalpinoideae. Revista Brasileira de Sementes, v.29, n.1, p.160-164, 2007.

EIRA, M. T. S.; FREITAS, R. W. A.; MELLO, C. M. C.. Superação da dormência de sementes de Enterolobium contortisiliquum (Vell.) Morong-Leguminosae. Revista Brasileira de Sementes, v.15, n.2, p.177-181, 1993.

FRANCO, E. T. H.; FERREIRA, A. G.. Tratamentos prégerminativos em sementes de Didymopanax morototoni (Aubl.) Dcne. et Planch. Ciência Florestal, v.12, n.1, p.1-10, 2002.

FREITAS, J. A. C.; CANDIDO, J. F.. Tratamento químico para abreviar a germinação de sementes de guapuruvú (Schyzolobium excelsum Vog.) e de mamoneira (Tachigalia multijuga Benth.). Revista Seiva v.32, n.76, p.1-10, 1972.

HERMANSEN, L. A.; DURYEA, M. L.; WHITE, T. L. Pretreatments to overcome seed coat dormancy in Dimorphandra mollis. Seed Science and Technology, v.28, n.3, p.581-595, 2000.

KISSMAN, C.; SCALON, S. P. Q.; FILHO, H. S.; RIBEIRO, N.. Tratamentos para quebra de dormência, temperaturas e substratos na germinação de Adenanthera pavonina L. Ciência Agrotécnica, v.32, n.2, p.668-674, 2008.

KONDO, T.. Promotion ofhard-seed germination in Lotus comiculatus var. japonicus for use in amenity grasslands. Seed Science and Technology, v.21, n.3, p.611-619, 1993.

LABOURIAU, L. G.. A germinação das sementes. Olimpia: OEA, 1983.

LOPES, J. C.; BARBOSA, L. G.; CAPUCHO, M. T.. Germinação de sementes de Bauhinia spp. Floresta, v.37, n.2, p.265-274, 2007.
LOPES, J. C.; DIAS, P. C.; MACEDO, C. M. P.. Tratamentos para acelerar a germinação e reduzir a deterioração de sementes de Ormosia nitida Vog. Revista Árvore, v.30, n.2, p.171-177, 2006

MAGUIRE, J. D.. Speed of germination: aid in selection and evaluation for seedling emergence and vigor. Crop Science, v.2, n.2, p.176-177, 1962.

SEMENEME, A. M.; POSSAMAI, E.; SCHUTA, L. R.; VANZOLINI, S.. Germinação e sanidade de Bauhinia variegata. Revista Árvore, v.30, n.5, p.719-724, 2006.

MARTINS, C. C.; CAMARA, A. T. R.; MACHADO, C. G.; NAKAGAWA, J.. Métodos de superação de dormência de sementes de barbatimão. Acta Scientarum Agronomy, v.30, n.3, p.381-385, 2008.

MATHEUS, M. T.; LOPES, J. C. Termoterapia em Sementes de Guapuruvú (Schyzolobium parahyba (Vell.) Blake). Revista Brasileira de Biociências, v.5, p.330-332, 2007.

MONTARDO, D. P.; CRUZ, F. P.; CAETANO, J. H.; BOLDRINI, I. I.; DALL' AGNOL, M.. Efeito de dois tratamentos na superação de dormência de sementes de cinco espécies de Adesmia DC. Revista Científica Rural, v.5, n.1, p.1-7, 2000.

MONTE, M. J. S.; BRANCO, A. C. L. C.; GOUVEIA, F. M. A.. Influência do processo de escarificação com ácido sulfúrico na germinação de sementes de Dimorphandra gardneriana Tul. 'fava-d'anta'. In: REUNIÃO NORDESTINA DE BOTÂNICA, 19. Anais. Recife: Sociedade de Botânica do Brasil, 1995.

NASCIMENTO, I. L.; ALVES, E. U.; BRUNO, R. L. A.; GONÇALVES, E. P.; COLARES, P. N. Q.; MEDEIROS, M. S.. Superação da dormência em sementes de faveira (Parkia platycephala benth). Revista Árvore, v.33, n.1, p.35-45, 2009.

NASCIMENTO, M. P. S. C. B.; OLIVEIRA, M. E. A.. Quebra da dormência de sementes de quatro leguminosas arbóreas. Acta Botânica Brasílica, v.13, n.2, p.129-137, 1999.

NEGREIROS, J. M. M.; FEITOSA, A. A. N.; OLIVEIRA, S. S.; FERREIRA, J. B.; NASCIMENTO, G. O.. Superação de dormência em sementes de Shizolobium amazonicum Ducke. Enciclopédia Biosfera, Goiânia, v.11, n.22, p.254-263, 2015.

NUNES, Y. R. F.; FAGUNDES, M.; SANTOS, M. R.; BRAGA, R. F.; GONZAGA, A. P. D.. Germinação de sementes de Guazuma ulmifolia Lam. (Malvaceae) e Heteropterys byrsonimifolia A. Juss. (Malpighiaceae) sob diferentes tratamentos de escarificação tegumentar. Unimontes Científica, v.8, n.1, p.43-52, 2006.

PAOLI, A. A. S.. Semente. In: SOUZA, L. A.. Anatomia do fruto e da semente. Ponta Grossa: UEPG, 2006. p.125-163.

POPINIGIS, F.. Fisiologia da semente. Brasília: Ministério da Agricultura, 1977.

RODRIGUES, E. H. A.; AGUIAR, I. B.; SADER, R.. Quebra de dormência de sementes de três espécies do gênero Cassia. Revista Brasileira de Sementes, v.12, n.2, p.17-27, 1990. 
SABIITI, E. N.. Ecological studies on Macroptilium atropurpureum Urb. in Rwenzori National Park, Uganda: Effects of pré-treating seeds with concentrated sulphuric acid, scarification, boiling and burning on germination. African Journal of Ecology, v.4, n.21, p.285-289, 1983.

SCALON, S. P. Q.; FILHO. H. S.; MUSSURY, R. M.; MACEDO, M. C.; KISSMANN, C.. Potencial germinativo de sementes de Dimorphandra mollis Benth. armazenamento, tratamentos pré-germinativos e temperatura de incubação. Cerne, v.13, n.3, p.321-328, 2007.

SEBASTINANI, R.; PETILLO, T. L.; CORNACHIONE, Y. G.. Influência de diferentes substratos e métodos de quebra de dormência na germinação de Schizolobium parahyba (Vell.) Blake (Fabaceae). Vitória: 2016.
SOUZA, E. R. B.; ZAGO, R.; GARCIA, J.; FARIAS, J. G.; CARVALHO, E. M. S.; BARROSO, M. R.. Efeito de métodos de escarificação do tegumento em sementes de $L$. diversifolia $L$. Pesquisa Agropecuária Tropical, v.37, n.3, p.142-146, 2007.

TELES, M. M.; ALVES, A. A.; OLIVEIRA, J. C. G.; BEZERRA, A. $M$. E.. Métodos para quebra da dormência em sementes de leucena (Leucaena leucocephala (Lam.) de Witl. Revista Brasileira de Zootecnia, v.29, n.2, p.387-391, 2000.

ZAIDAN, L. B. P.; BARBEDO, C. J. Quebra de dormência em sementes. In: FERREIRA, A. G.; BORGHETTI, F.. Germinação: do básico ao aplicado. Porto Alegre: Artmed, 2004. p.135146. 